\title{
MORPHOLOGICAL SIGNS OF GUNSHOT INJURIES OF THE FLAT BONES THAT ALLOW YOU TO ESTABLISH THE DIRECTION OF THE ROTATION OF A FIREARMS PROJECTILE
}

\section{S.V. Leonov ${ }^{I}$, A.V. Mikhaylenko ${ }^{2}$}

Abstract. It has been established that the morphological signs in firearm fractures of the flat bones coincide according to its topography and the degree of a marked character with separate elements of the fields of power voltages in the mathematical model.

Keywords: fractures, rotation of projectile, barrel rifling.

${ }^{1}$ Department of Medico-Craminalistic Identification of the $111^{\text {th }}$ STCFM CE (Moscow)

${ }^{2}$ The City Clinical Bureau of Forensic-Medical Examination (Kiev)

Рецензент - проф. В.Т. Бачинський

Buk. Med. Herald. - 2013. - Vol. 17, № 3 (67), part 1. - P. 93-96

Надійшла до редакції 06.06.2013 року

(ㄷ С.В. Леонов, А.В. Михайленко, 2013

УДК 612.12-001.45:340.624

${ }^{1}$ С.В. Леонов, ${ }^{2}$ А.В. Михайленко, ${ }^{3}$ А.В. Слаутинская

\section{ОСОБЕННОСТИ И МЕХАНИЗМ ФОРМИРОВАНИЯ КРОВОПОДТЕКОВ ПРИ ТРАВМЕ ЭЛАСТИЧНЫМИ СНАРЯДАМИ}

\author{
${ }^{1}$ Московский государственный медико-стоматологический университет \\ ${ }^{2}$ Киевское городское клиническое бюро судебно-медицинской экспертизы \\ ${ }^{3}$ Национальная медицинская академия последипломного образования им. П.Л. Шупика
}

Резюме. Проведено исследование морфологии контурных кровоподтеков на практических наблюдениях, которые образовались от воздействия эластичных снарядов при выстрелах из травматического оружия. Установлено, что морфологические признаки контурных кровоподтеков обусловлены особенностями механики разрушения тканей. Метрические данные морфологических особенностей контурных кровоподтеков и

Огнестрельная травма человека является одним из самых изученных и до сих пор изучаемых разделов судебной медицины. В существующей отечественной литературе освещены вопросы, начиная от конструктивных особенностей боеприпасов и оружия, всевозможные условия и виды взаимодействия огнестрельных снарядов и тела человека, много работ посвящено изучению ран и раневых каналов, включая и молекулярное сотрясения тканей и т.д. А вот ушибающему действию снаряда внимания уделено не столь много, если не сказать, что практически вообще не уделялось. По данным В.Л. Попова, ушибающее действие пули, обладающей малой кинетической энергией, проявляется образованием на теле ссадин, кровоподтеков, поверхностных ушибленных ран. Наши оригинальные наблюдения показали, что при воздействии эластичного огнестрельного снаряда образуются преимущественно именно такие повреждения [2, 5].

Нами рассмотрены несколько механизмов образования кровоподтека при ушибающем действии огнестрельного эластичного снаряда и использованием данных теоретической механики. Собственно контакт и внедрение снаряда в тело,

(c) С.В. Леонов, А.В. Михайленко, А.В. Слаутинская, 2013

96 эластичного снаряда совпадают с размерным соотношением в модели указанного взаимодействия - воздействие тупого индентора на упругопластическое полупространство.

Ключевые слова: механика образования кровоподтека, эластичный снаряд.

внедрение тупого индентора в изотропное упругое полупространство. Реакция на внедрение снаряда тканей организма, которые представляют собой неоднородную (анизотропную) среду, рассмотрены как работа основания Винклера и сдвиг слоев.

Контакт тупого индентора с поверхностью изотропного упругого полупространства изобра-

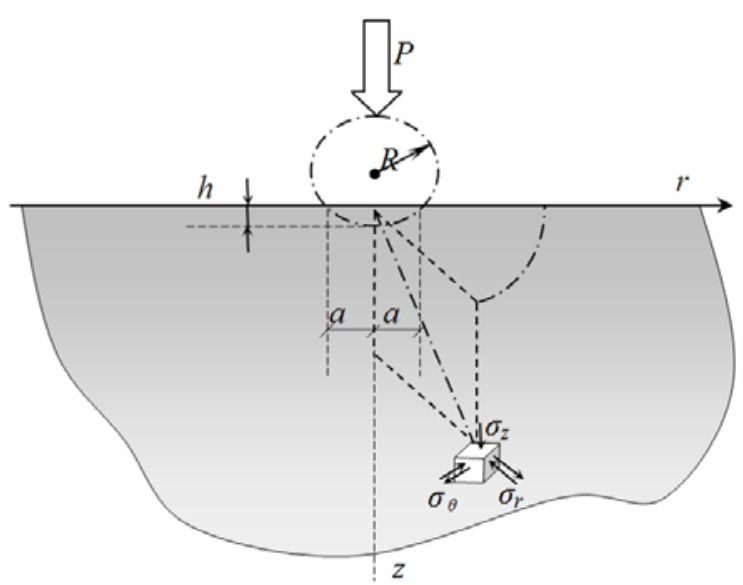

Рис. 1. Точечный контакт тупого индентора с поверхностью кожного покрова 


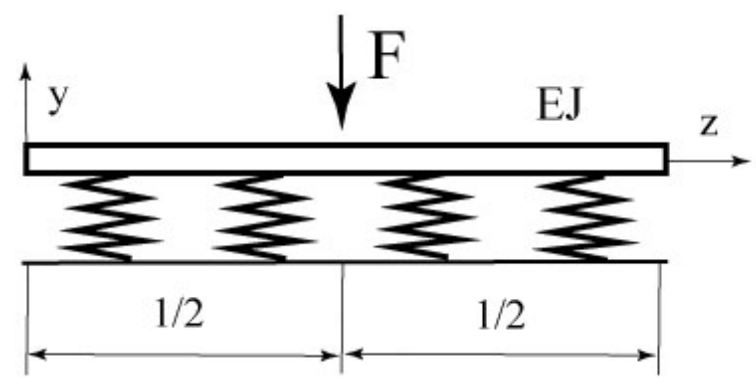

$a$

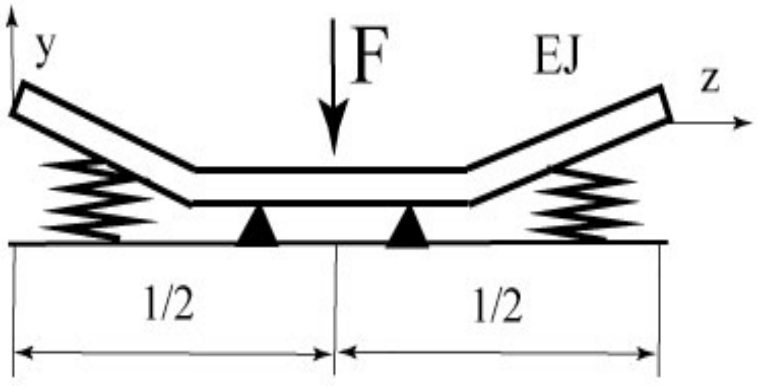

$\sigma$

Рис. 2. Реакция упруго-податливой подложки (основания Винклера) при нагружении

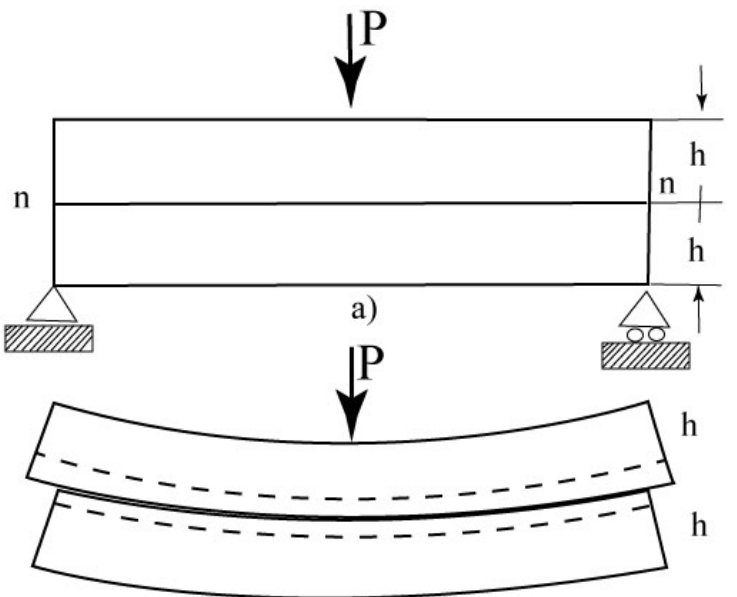

б)

Рис. 3. Деформация двух одинаковых прямоугольных стержней

жен на рис. 1. При контакте тупого индентора с упругим полупространством в окрестности контактной поверхности все главные напряжения сжимающие, что приводит к развитию в области контакта состояния, близкого к гидростатическому сжатию (материал сжимается по всем трем направлениям одинаково). В состоянии гидростатического сжатия разрушение материала невозможно [3, 4].

На основании локализации сдвиговых деформаций следует ожидать наличия кровоизлияний вокруг места внедрения в полупространство. Кровоизлияния должны быть выявлены (при послойном исследовании повреждения) в виде зоны, имеющей вид полусферы окружающей место удара эластичным снарядом.

Также мы попытались установить деформационные процессы и их локализацию, на этапах взаимодействия эластичного снаряда с кожей и подлежащими ей мягкими тканями (жировая клетчатка, мышцы) на примере упруго-податливой подложки - основании Винклера, в роли которой выступала подкожно-жировая клетчатка и мышечная ткань. Рассмотрим эластичный огнестрельный снаряд, который будет воздействовать на поверхность упругого многослойного материала (кожа и подлежащие ей мягкие ткани), который в свою очередь, под действием нагрузки, будет опускаться на глубину. Особенность работы основания Винклера заключается в том, что при нагружении подложка (она отмечена на схеме в виде пружин) достаточно легко смещается в направлении действия силы (cм. puc. 2 a), а затем, подложка (жировая клетчатка, мышцы) достигает предела податливости и приобретает жесткость и больше не сжимается (см. рис. 2б).

Итак, соответственно наибольшему прогибу кожи, формируется наибольшее сжатие материала подложки, в нашем случае это место контакта огнестрельного снаряда с кожей. В этот момент, когда предел на сжатие достигнут ткани подложки в месте контакта с огнестрельным снарядом, перестают сжиматься и переходят в упругое состояние. При достижении данного состояния в толще материала (жировая клетчатка, мышцы) формируется зона гидростатического сжатия [1]. А поскольку в зоне гидростатического сжатия материала разрушение материала невозможно, то из этого следует, что соответственно этой зоне мягкие ткани повреждаться не будут, что в кровоподтеке на коже будет выглядеть центральным участком просветления. В окраске кровоподтека самая интенсивная или выраженная зона будет периферическая, где максимально расположены повреждения сосудов мягких тканей.

Существование касательных напряжений в плоскостях, параллельных нейтральной плоскости, возможно показать на примере двух одинаковых прямоугольных стержней, положенных просто один на другой, опёртых на две опоры, как показано на рис. $3 a$, и изгибаемых сосредоточенным грузом $P$. Если между стержнями нет трения, изгиб каждого стержня будет независимым от изгиба другого. У каждого из стержней будут сжаты верхние и растянуты нижние продольные волокна, при этом деформация будет такой, как показано на рис. 3б. Нижние продольные волокна верхнего стержня сместятся относительно верхних волокон нижнего стержня. В сплошной среде такой же высоты (2h) возникают касательные напряжения такой величины, что они предотвращают смещение верхней части относительно нижней, как показано на рис. 36. Благодаря этому отсутствию смещения центральный стержень толщиной $2 \mathrm{~h}$ значительно жестче и прочнее, чем два стержня, каждый высотой h [5].

Кожа с подлежащими ей подкожной клетчаткой, фасциями и мышцами представляет собой многослойный материал, между слоями которого имеются плотные связи, предотвращающие трение между ними. Однако следует учесть, что 


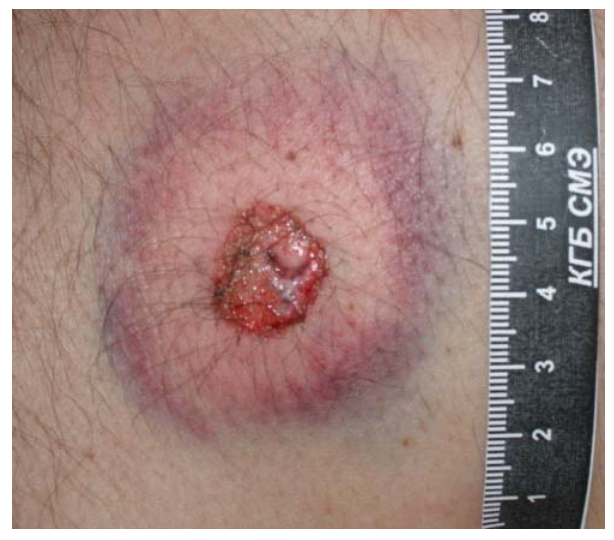

a

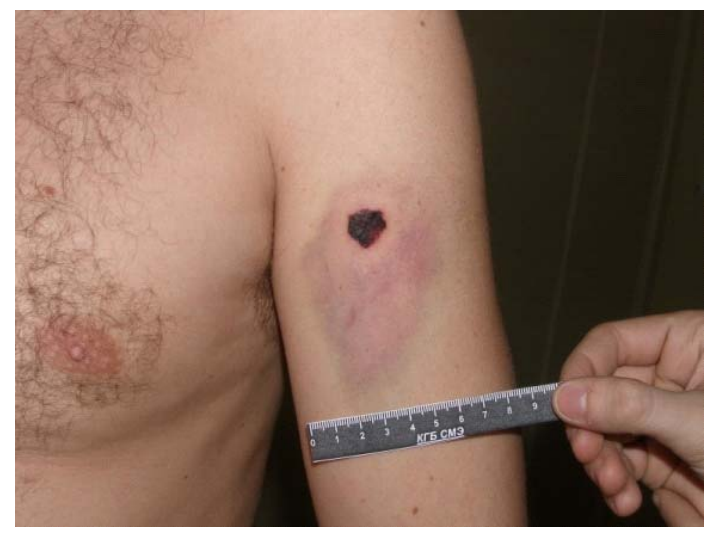

6

Puc. 4. Внешний вид контурных кровоподтеков, которые образовались в результате воздействия эластического огнестрельного снаряда перпендикулярно (а) и под углом (б) к поверхности кожи

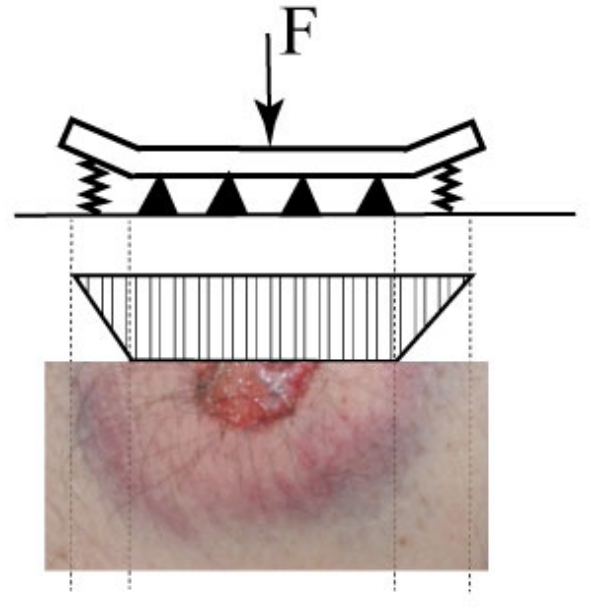

a

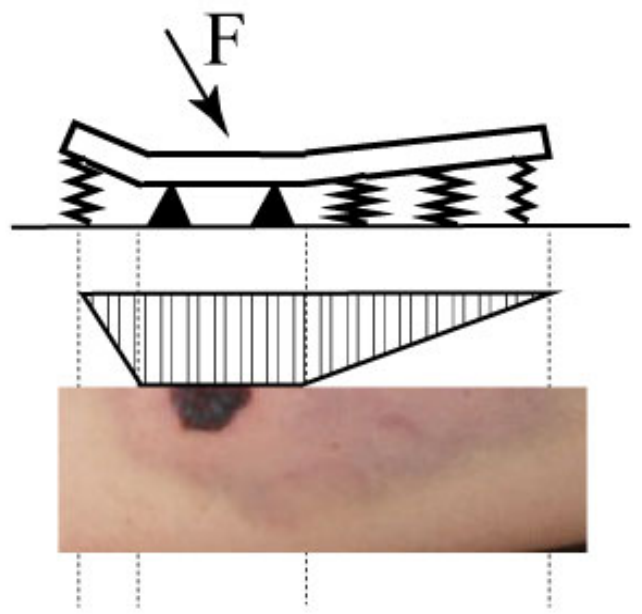

б

Рис. 5. Эпюры силовых напряжений

эти слои имеют различающуюся между собой эластичность и упругость, что будет обуславливать вышеуказанное смещение между слоями и как следствие этого повреждение структур между ними при изгибе.

При перпендикулярном воздействии снаряда (индентора) на поверхность кожи, будут образовываться кровоподтеки округлой формы, как показано на puc. 4a. При воздействии снаряда под углом к поверхности кожи, т.е. смещении центра изгиба на плоскости, кровоподтеки будут приобретать удлиненную форму, при этом вытянутая и более тонкая их часть будет соответствовать развернутому углу, т.е. направлению движения огнестрельного снаряда, как показано на рис. 46.

Для проверки полученных данных, нами предпринят математический анализ характера деформаций методом сечений с построением эпюр деформаций, возникающих при нагружении жировой ткани. Изгибающий момент и прорезывающая сила имеют одно и то же направление, поэтому они положительны. Прорезывающая сила остается постоянной для всех сечений слева и справа от нагрузки, а изгибающий момент изменяется прямо пропорционально расстоянию от места действия силы до точки опоры как в пре- дыдущих наблюдениях, и представляет собой усеченную пирамиду - что является следствием влияния основания Винклера (рис. 5 a, б).

Построенные эпюры показали, что критическое сечение соответствует проекции воздействия внешней силе, и располагается на противоположной поверхности балки, что соответствует полученной в ходе исследования морфологии повреждений.

\section{Вывод}

Таким образом, проведенное нами теоретическое обоснование механизма образования кольцевидного кровоподтека при ушибающем действии пули показало сложность и многогранность процессов, происходящих в биологических объектах при их нагружении. Вместе с тем, исследование показало и широкие возможности механики деформированного твердого тела для решения прикладных задач судебно-медицинской экспертизы.

\section{Литература}

1. Леонов С.В. Рубленные повреждения кожного покрова и костей/ С.В. Леонов. - Хабаровск , 2006. - С. 274.

2. Молчанов В.И. Огнестрельные повреждения и их судебно-медицинская экспертиза / В.И. Молчанов, 
В.Л. Попов, К.Н. Калмыков. - Ленинград: Медицина, 1990.- C. 270.

3. Морозов Е.М. Контактные задачи механики разрушения / Е.М. Морозов, М.В. Зернин. - М.: Машиностроение, 1999. - С. 49-53.

4. Мусин Э.Х. Судебно-медицинская характеристика повреждений из газового оружия эластическими сна- рядами травматического действия: автореф. дис. на соиск. уч. степ. канд. мед. наук. - Москва, 2006. - 30с.

5. Попов В.Л. Судебно-медицинская баллистика / В.Л. Попов, В.Б. Шигеев, Л.Е. Кузнецов. - СПб.: Гиппократ, 2002. - С. 656.

\title{
ОСОБЛИВОСТІ І МЕХАНІЗМ УТВОРЕННЯ СИНЦІВ ПРИ ТРАВМІ ЕЛАСТИЧНИМИ СНАРЯДАМИ
}

\author{
С.В. Леонов ${ }^{1}$ О.В. Михайленко ${ }^{2}$, О.В. Слаутинська
}

Резюме. Проведене дослідження морфології контурних синців на практичних спостереженнях, які утворилися від дії еластичних снарядів із травматичної зброї. Встановлено, що метричні ознаки контурних синців зумовлені особливостями механіки руйнування тканин. Метричні дані морфологічних особливостей контурних синців та еластичного снаряда збігаються з розмірним співвідношенням у моделі вказаної взаємодії - дія тупого індентора на пружнопластичний напівпростір.

Ключові слова: механіка утворення синця, еластичний снаряд.

\section{THE SPECIFIC CHARACTERISTICS AND THE MECHANISM OF THE FORMATION OF BRUISES IN CASE OF AN INJURY BY ELASTIC PROJECTILES}

\section{S.V. Leonov ${ }^{1}$, A.V. Mikhaylenko ${ }^{2}$, A.V. Slautinskaya ${ }^{3}$}

Abstract. A study of the morphology of contour bruises during practical observations which were formed from the action of elastic projectiles in case of shots from traumatic weapon has been carried out. It is established that the morphological signs of contour bruises are stipulated by the special features of the mechanics of destructing tissues. The metric data of the morphological special features of contour bruises and an elastic projectile coincide with the dimensional relationship in the model of the said interaction - the action of a dull an obtuse indentor on the elastic-plastic half-space.

Key words: mechanics of bruising, elastic projectile.

${ }^{1}$ State Medicostomatological University (Moscow) ${ }^{2}$ City Clinical Bureau of Forensic Examination (Kiev) ${ }^{3}$ P.L. Shupic Medical Academy of Post-Graduate Education (Kiev)

Рецензент - проф. В.Т. Бачинський

Buk. Med. Herald. - 2013. - Vol. 17, № 3 (67), part 1. - P. 96-99

Надійшла до редакції 12.06.2013 року

(C) С.В. Леонов, А.В. Михайленко, А.В. Слаутинская, 2013

УДК 340.6

\section{Е.Н. Леонова ${ }^{1}$, М.Н. Нагорнов ${ }^{1}$ Е.Н. Кошелева ${ }^{2}$ \\ ОСОБЕННОСТИ ОТПЕЧАТКОВ ВОЛОС ГОЛОВЫ, ПРОПИТАННЫХ КРОВЬЮ}

Первый Московский государственный медицинский университет им. И.М. Сеченова Бюро судебно-медицинской экспертизы, Москва

\footnotetext{
Резюме. Авторы статьи на основании экспериментальных исследований выявили морфологические признаки отпечатков окровавленных волос, определили
}

зону максимального контакта следообразующего предмета и следовоспринимающей поверхности.

Ключевые слова: контактные следы крови, отпечатки.

Введение. Следы крови на месте обнаружения трупа играют существенную роль в раскрытии преступлений. Особое место занимают контактные отпечатки. При этом на следовоспринимающих поверхностях могут отпечатываться различные следообразующие предметы: пальцы рук, подошвенные поверхности стопы, подошва обуви, поверхность травмирующего орудия и др.

(C) Е.Н. Леонова, М.Н. Нагорнов, Е.Н. Кошелева, 2013
В некоторых случаях отпечатки могут иметь важное идентификационное значение [1].

В практике судебно-медицинского эксперта могут встретиться отпечатки окровавленных волос головы. Их особенности не освещены в доступной судебно-медицинской литературе, что и послужило основанием проведения настоящего исследования. 